\title{
The Most Resilient Show on Earth: The Circus as a Model for Viewing Identity, Change, and Chaos
}

\author{
Philip A. Loring ${ }^{1}$
}

\begin{abstract}
Resilience, adaptability, and transformability are all tightly linked to the notion of change, whether in respect to coping with, adapting to, or harnessing it. But in order to understand these forces of change, we first need to recognize its counterpart: identity. Identity of a social-ecological system is not merely a static set of quantifiable feedbacks or indicators, but a more qualitative characterization of what results from the overlap of the social and the ecological. To fully articulate these ideas, I turn to a unique and enduring phenomenon: the traveling circus. Through the many forms they have taken over the last 150 $\mathrm{yr}$, circuses have changed significantly while sustaining a singular identity. As a successful and enduring social system, their intriguing history exposes the nuances of sustainability theory, from resilience to pathologies, and illustrates that sustainability requires a complex dynamic between identity, tradition, and change.
\end{abstract}

Key Words: adaptive management; circus; panarchy; resilience; sustainability; tribe; tribalism.

\section{INTRODUCTION}

"Sustainability requires both change and persistence" (Holling et al. 2002:396). At first glance, this statement seems to be a contradiction. However, with this paper I hope to show how the art of sustainability lies in realizing mutualism, rather than tension between change and persistence, and to do so means first coming to terms with the notion of identity. When we capture the identity of a system, not only do we achieve a baseline for managing for its persistence, we also gain the ability to recognize, understand, and manage change.

Identity is a bit of a conundrum, as Cumming and Collier (2005) remind us by way of the philosophical riddle of Theseus' ship. When Theseus returned to Greece after besting the Minotaur, it was decided that his vessel would be preserved. It was kept moored, and carefully maintained; as needed, timbers, ropes, and sails were replaced, and eventually the entire ship had been rebuilt, albeit one piece at a time. The riddle asks how, when every last piece of the ship has been replaced, can we still consider the vessel to be the same as that which belonged to Theseus? Cumming and Collier answer this question by recommending that identity be considered as a function of continuity through space and through time; in order to explore this riddle and their answer, I turn to a unique but familiar social-ecological system: the traveling circus.

The circus has transformed itself significantly over the years, often going so far as to discard attractions that were once its most emblematic. Nevertheless, its singular identity persists; one still recognizes the circus when they see it. If a community of people can, over time, almost completely transform their way of life, while continuing to both self-identify and be outwardly recognizable as the same culture, some "key system components" as described by Cumming and Collier are sure to be apparent.

For this paper I collated a wide variety of sources, including historical records, memoirs, newspaper articles, and first-hand accounts, and frame the circus as both a didactic and serviceable model for exploring sustainability. Most of my research focuses on the traveling circus of 19th and 20th century America, for which there exists an extremely well documented history. As I detail below, its fascinating story reveals many nuances of resilience theory and of the adaptive cycle. It

${ }^{1}$ University of Alaska, Fairbanks 
proves to be an example that reveals much about the nature of identity for social-ecological systems, and in doing so reveals how change and persistence need not always be considered at odds.

\section{THIS WAY TO THE BIG SHOW}

Though many elements of the circus have existed for thousands of years, e.g., acrobats, jugglers, and clowns, that which we call "circus" was born right around the same time as the United States of America. Like America, its colorful past is described in half-legend, half-fact. The circus's origins are in trick horseback-riding shows, which appeared first in London under the direction of Philip Astley, and then shortly after in Philadelphia, New York, and Boston (Fox and Parkinson 1969, Wilmeth 1982, Stoddart 2000). The first American acts also included a lone clown and a few musicians. In 1793 John Bill Ricketts started his "combination riding circus," which most consider to be the first official circus in America. He established permanent auditoriums for the show in New York, Philadelphia, Boston, and Salem; legend has it that President George Washington attended many of these first shows (Fox and Parkinson 1969, Stoddart 2000).

Over the next two decades, the circus developed into the attraction we know today. The iconic elephant appeared for the first time in 1816 as a part of the Nathan Howes Roadshow, though many circus owners of the early 1900s attributed the event to their own great grandfather, and its popularity sparked the many great menagerie shows that followed; interestingly, churchmen had begun raising moral objections to the circuses, and animal menageries seemed free of such criticism. These new animal acts met with such success that a great number of new companies sprung up. In the 1820 s many of these menageries collaborated to found the Association of the Zoological Institute, which by assigning territories and planning routes hoped to bring some regulation to an industry that was becoming frighteningly competitive.

The Zoological Institute was actually the work of a cartel that had formed between a handful of powerful circus owners, who called themselves the Flatfoot Party (Fox and Parkinson 1969). The Flatfoots financed new circuses, leased equipment, animals, and sometimes entire menageries to touring groups. They grew into a syndicate, which bordered on organized crime, leveraging the monopolistic power they accrued through their various businesses, along with some rather aggressive, sometimes criminal tactics to assert territoriality for and control over their numerous shows.

In 1837, a nationwide bank failure, often called the Panic of 1837 , followed by a 5 -yr economic depression struck down the Zoological Institute and most of the existing circuses. However, the businessmen and showmen quickly recovered, faster in fact than the rest of the nation, thanks to the hidden influence of the Flatfoots. They regrouped and resumed their trouping, often under banners of new alliances (Fox and Parkinson 1969). The period that followed, up until the Civil War, was a firestorm of activity that included regular splitting, acquisition, and merging of shows. During this time, some of the timeless names of circusing appeared, including Phineas Taylor Barnum, the Ringling Brothers, and George Bailey. The circus parade, an event that would become one of its most iconic, also first appeared during this period.

In contrast to the disarray that began in 1837 , the industry had a mixed, but generally positive response to the Civil War. Some could not avoid being closed down by the fighting, but most were able to continue touring, carefully working their way through both Confederate and Union Territory. In 1862, the Spalding and Rogers circus decided to avoid the war altogether, and took their circus on tour through South America (Fox and Parkinson 1969). Interestingly, the North-South rivalry also split up one marriage, resulting in a mother-son venture to start the W.W. Cole Circus, which featured horseback rider Miles Orton, who went on to become one of the most financially successful circus performers in history.

Following the Civil War, circuses enjoyed what would be their golden years (Fox and Parkinson 1969, Stoddart 2000). Touring companies began to settle into their economic niches, with smaller circuses focusing on rural America, while the larger ones competed to be the number-one circus in every major American city. Many of the larger shows consolidated; Barnum and Bailey and Adam Forepaugh's shows emerged as the two largest organizations, often competing for venues and acts, and often purchasing or bailing out smaller, failing shows. By the 1920s, most large circus names were either owned by the Ringling Corporation, e.g., 
Barnum and Bailey's combined shows, or the American Circus Corporation, e.g., Sells-Floto, Hagenbeck-Wallace, Buffalo Bill's Wild West, etc. Around this time is also when the big top first appeared; up to this point troupes still performed in fixed venues like community halls and civic centers. The circus, as we conceive of it today, was now fully formed.

\section{RESILIENCE UNDER THE BIG TOP}

Traveling circuses had to deal with shifting economic, political, and social landscapes at every stop. The advance crews, responsible for planning and advertizing a circus's yearly route, were expected to stay intimately familiar with the state of local economies. With this knowledge and a little creativity, the circus was able to mitigate the negative influences of performing in a financially struggling community. They knew which crops communities depended on, the timing of the harvest, and were aware of labor strikes, and even the timing of paydays. If their next stop was in some kind of economic distress, the circus might change the scale and/or nature of its show, or perhaps skip the stop altogether (Fox and Parkinson 1969, Powledge 1976).

Circuses were able to adapt and respond to the unpredictable economic and political landscape because of their skillful economic diversification. There were two kinds of shows, the "low-grass" and the "high-grass" shows. Larger shows that played the urban, more sophisticated communities were called low-grass because the grasses and weeds were kept cut, whereas the high-grass shows, also called a mud show, played the back hills, the small towns, and the crossroad communities (Fox and Parkinson 1969). Most had a very deep reservoir of repertoire and could adjust their fare to suit the economic standing and moral sensibilities of each audience.

One common example of this happened when circuses visited bible-belt communities. Churches often strongly resisted the visiting circus, considering them purveyors of sin. Rather than skip these stops altogether, some shows adapted their performances in order to appease the religious activism, sometimes creating elaborate nativity recreations with circus animals, and even by disguising their show as religious revivals (Fox and Parkinson 1969, Fenner and Fenner 1970, Oxley 2005, personal communication).

Needless to say, the flexibility and mobility that allowed the circus to survive contributed an equal share of logistic difficulties. Fortunately, an organic solidarity or connectedness resulted from the diversity of role and responsibility of circus members, which made the great show resilient to these difficulties. Each member of a touring company was critical to its success, and they either performed their duties or could not remain (Zuckoff 1992, Quinn 1999, Oxley 2005, personal communication). Also, though there were clearly defined social lines between performers, businessmen, and roustabouts, i.e., laborers, each felt their station to be the best, or most important, and for good reason. When the big top was being erected, no one in the circus was more important than the riggers; when the show began, there was no one more important than the performers; and the show would not go on at all were it not for the efforts of the advance crew and the 24-hour man (Fox and Parkinson 1969, Powledge 1976, Fenner and Fenner 1970, Oxley 2005, personal communication). Loyalties to one's show and to tradition kept circuses going in fair weather and in mud, in rich times and even in those years when the circus could feed them and house them, but not pay them (Fox and Parkinson 1969).

In these respects, circuses functioned much like tribes (Quinn 1999), and circus members' loyalty to their tribe and tradition also provided the system with a great deal of built-in resistive capacity. Tradition insisted that the show must go on, no matter the cost, and members of the circus would often stray far outside the traditional parameter of their jobs to see that this happened. Though we would not expect a circus boss to be capable of walking the tightrope or juggling clubs, he was perfectly capable of swinging a sledgehammer when need be. In fact, bosses and aging performers would often pick up the slack for operational responsibilities (Fox and Parkinson 1969, Oxley 2005 , personal communication). Also, because so many generations of family members traveled together, should a performer be injured, the show could go on with a slightly altered cast (Powledge 1976). 


\section{WHAT IS THE CIRCUS?}

"Many circus historians would agree that the ring and the performing horse are the very foundations of the circus, but even this relatively flexible definition would exclude many individual and collective modern performances which... we have learnt to call circus. At the same time, the glorious and diverse array of acts, e.g., clowns, trapeze and high-wire artists, jugglers, and so on, though we may find them on vaudeville stages, street corners, or country fairs, can be argued to belong to the circus because their performances in some way embody a characteristic circus energy or aesthetic" (Stoddart 2000:3-4, emphasis added).

The look of the circus changed dramatically throughout its 200+ yr history. Freak shows were completely abandoned, and performing animals were largely phased out. Even the circus parade, a high-energy display that announced the circus had come to town, which was one of its most iconic spectacles, was abandoned in the early 1900s because of civic and economic pressures (Fellows and Freeman 1932; Wilmeth 1982).

With all of these changes, the problem of linking the circus of today with the circus of the past begins to resemble the problem of Theseus' ship. As Stoddart suggests in the quote above, in order to answer this question we need to understand the difference between "the" circus and "circus," between the institution, and the energy, or aesthetic of the institution. "The" circus is the institution: a circus, many circuses, or all the circuses that have ever been. But "circus" is something less tangible, a combination of spectacle with the unique and intimate connection that occurs between the performers and the audience, and evokes words like "exotic," "anticipation," and "awe." Though the circus looks far different today than it did in the 1800 s or the 1900 s, circus is the "key system property" that persists and allows us to know one when we see it.

One of the places we still find this aesthetic is in the circus's name. There have been literally thousands of circuses to tour America under perhaps twice as many names, but for the most successful ones, their names emerged as representative of this relationship between the circus and the audience. Elaborate circus titles first emerged in a period when patents and trademarks held special importance in the eyes of Americans, so they reflected not just the size or glamour of the entertainment alone, but also qualities of respectability, confidence, honesty, and tradition. Well known names were billed together so frequently that the titles of circuses became very long: "Ringling Bros. Barnum and Bailey Combined Shows" and "The Adam Forepaugh \& Sells Brothers Great Shows Consolidated" were two of the longest and most well known names. Notice the curious lack of the word "circus" in both titles (see also Figs. 1 and 2); the names meant "circus" more so than did the word circus itself!

\section{THE ADAPTIVE BIG TOP}

"By 1968 the circus business was at another of its periodic low points and was poised for still another recovery and revitalization. ... [and] John Ringling North sold his circus. ... Once again the indomitable circus business was moving to the high side of its endless cycle" (Fox and Parkinson 1969:128).

The preceding sections are intended to reveal the circus industry as a landscape of complex, adaptive systems, each traveling the adaptive cycle at a variety of scales: from the smallest of the performerfamilies, up through individual circuses, and to the circus industry as a whole.

From this point of view, some questions can be asked about the circus's history that have useful answers. Why, for instance, was the industry able to dodge any serious effects of the American Civil War but not World War II? Why did it recover so quickly from Great Panic but not from the Great Depression? This variety in adaptive response proves usefully illustrative of the scalar dynamics of social systems; in each of these cases the state of the industry at larger scales directly influenced the adaptive capacity of smaller scales, and in many cases vice-versa.

The social structures of circuses and their performing families were constantly in flux; another way circuses functioned like tribes (Parkinson 1999, Trosper 2003). As performing families grew in size and reputation, they often split; it was also very common for circuses to team up and share their names. As acts gained esteem, other circus owners might recruit these performers or combine shows (Bergengren 1909, Grossman 1986, Zuckoff 1992, Quinn 1999). Marriages brought performing groups together, and divorces split them apart. At one point, 
Fig. 1. Circus names conveyed much to their audience, and many are as recognizable today as they were $100 \mathrm{yr}$ ago. This poster of the Ringling Bros. and Barnum \& Bailey combined shows is from 1900. Note the lack of the word "circus" on both of these banners. From the Library of Congress, Reproduction \# LC-USZC4-9675.

Image courtesy of Circus World Museum, Baraboo, Wisconsin with permission from RINGLING BROS. AND BARNUM \& BAILEY ${ }^{\circledR}$ and THE GREATEST SHOW ON EARTH ${ }^{\circledR}$.

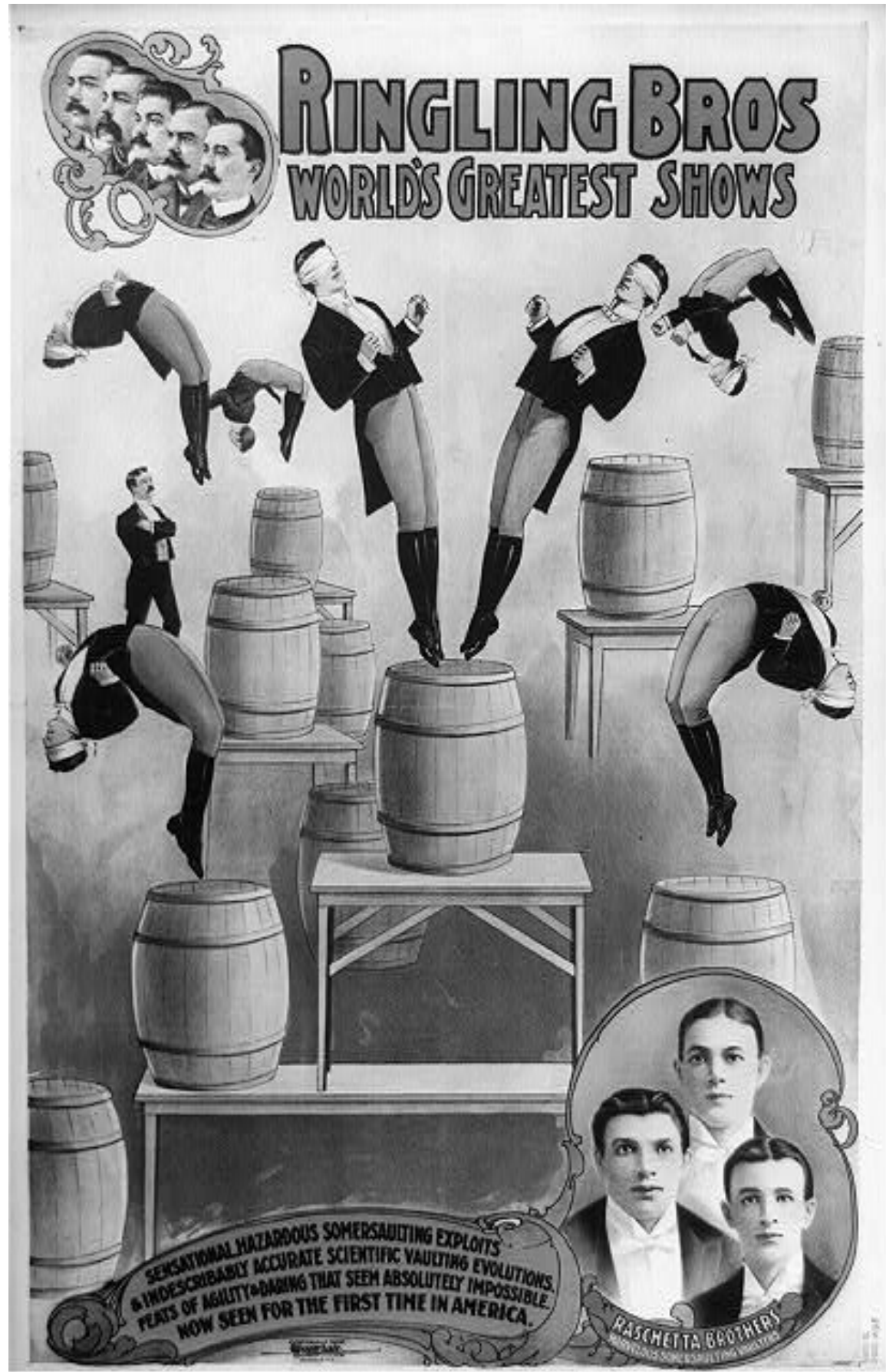


Fig. 2. Circus names conveyed much to their audience, and many are as recognizable today as they were $100 \mathrm{yr}$ ago. This poster is for the combined Adam Forepaugh and Sells Brothers circus. Note the lack of the word "circus" on this banner. From the Library of Congress, Reproduction \# LC-USZC4-5227.

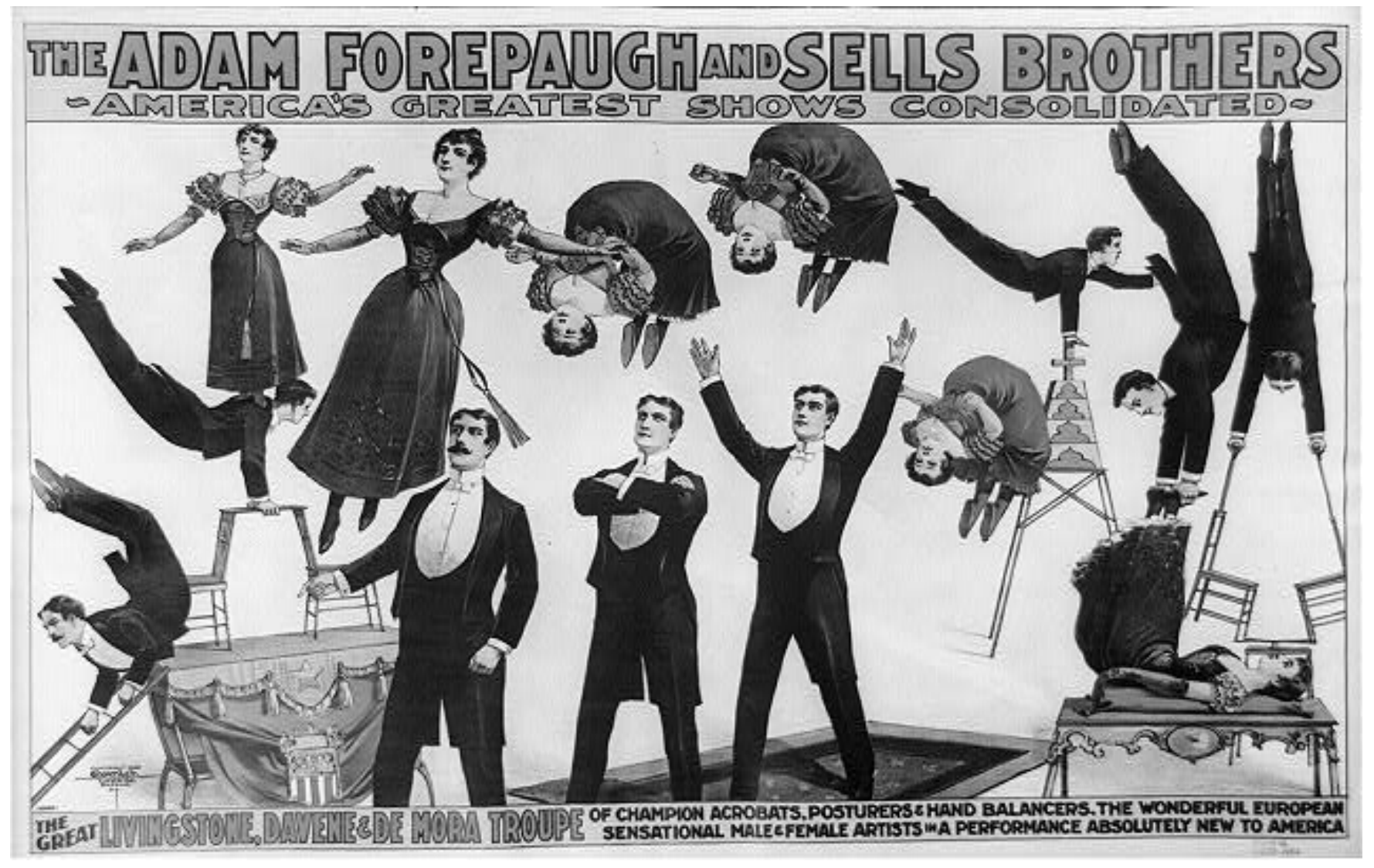

The Flying Wallendas, a family of successful trapeze and tightrope artists, were a main attraction at three different circuses (Fenner and Fenner 1970). This ongoing process of release, which through a short lens appears somewhat chaotic, served as a stabilizing force at the larger industry scale. It measured any unhealthy accumulation of potential, in terms of human capital, because there were always opportunities for new partnerships, and connectedness or rigidity, by fostering social flexibility.

In 1837 , still so relatively early in the life of the circus, most performing families were still in their first generation. Many of the other sinks of resilience as described earlier, particularly those that fostered connectedness, e.g., solidarity between performers or name-recognition with the audience, had not yet developed, so the circus disbanded rather readily. However, The Flatfoot Party was rather well established and able to guide the industry's ensuing reorganization (Fox and Parkinson 1969).

\section{The Great Depression and the chaos trap}

The circus industry was unable to emerge so smoothly from the cascade of damage inflicted upon it by the stock market crash of 1929 and the Great Depression. Smaller circuses like the John Robinson Circus, a troupe that had seen $90 \mathrm{yr}$ of circusing closed down altogether. John Ringling, prior to the crash, had purchased many of the largest touring circuses; even though many of them, like 
the Hagenbeck-Wallace show, continued to present outstanding performances for the next couple of years, the Ringling kingdom eventually found itself mired in financial difficulty like everybody else. Circus companies came and went through the war years and the following few decades as the industry struggled to reorganize, seemingly trapped in a perpetual state of chaos (Fox and Parkinson 1969).

Human capital was extremely high for the circus during these years because of the large number of unemployed performers. However, they were not able to settle down with a particular company because companies rarely lasted for more than a season before going defunct (Clement 1974). The constant opening and closing of shows meant that there was little opportunity for solidarity to develop between performers, so any kind of resilience and connectedness remained nearly absent from the industry. Also, new start-up circuses came and went so frequently that none were able to establish the important name-relationship with their audiences. Even Ringling Bros., the only recognizable name to survive, was forced to stop touring mid-season three times in a $20 \mathrm{yr}$ period (Fox and Parkinson 1969), damaging its reputation considerably. As a result, the relationship between circuses and their audiences, which represented the industry's most valuable reservoir of resilience and connectedness, atrophied.

The industry's inability to draw from these sinks of resilience and connectedness sent the industry into what proved to be an inescapable chaos. A general trend of economic uncertainty continued to plague the country throughout the post-depression years. Circuses tried desperately to innovate; Ringling Bros. introduced Gargantua the Gorilla in an attempt to capitalize on the popularity of King Kong. Others gave their circuses patriotic themes or sold U.S. War Bonds, but the lack of a committed and loyal audience kept any long-term cohesion at bay (Truzzi 1968, Fox and Parkinson 1969, Fenner and Fenner 1970, Stoddart 2000).

Resilience theory describes eight possible combinations of potential, connectedness, and resilience, four of which are captured by the four phases of the adaptive cycle, and four of which are pathologies, i.e., maladaptive states that represent departures from, or collapses of the adaptive cycle (Holling and Gunderson 2002; Holling et al. 2002, Allison and Hobbs 2004). Holling et al. (2002) detail two of these: the poverty trap and the rigidity trap, followed by Allison and Hobbs (2004) who coined of the third, "lock-in" trap (see Table 1 for a breakdown of these pathologies and their respective levels of potential, connectedness, and resilience). The circus's inability to emerge from reorganization does not, however, fall within one of these three. Instead, it provides an example of a system caught in the fourth, previously unidentified system pathology, which I call the "chaos trap" (Fig. 3).

"The shift from [release] to [reorganization] represents a sudden, explosive increase in uncertainty. It is the phase in which conditions might arise for formal chaotic behavior" (Holling and Gunderson 2002:45).

Normally, this chaotic period results in the creation and maintenance of diversity within a system, which is the "stuff" of a system's adaptive capacity and adaptive response (Holling and Gunderson 2002). However, if levels of resilience and connectedness are too low, as they were with the circus, new partnerships within a system remain precarious and break apart when placed under even low levels of stress. For the circus, this meant that acts were not able to develop the sort of resilience that would be needed in order to survive the economic hardships of the war years that followed.

\section{DOES THE SHOW STILL GO ON?}

"The circus is better than it used to be; and it is, at the same time, not as big. It is a different time and a different place, and the circus plays to different audiences. However, audiences now, as in earlier times, are impressed and entertained by the wonder of humans and animal performers doing incredible things" (Clement 1974:146).

In the early $1960 \mathrm{~s}$, circuses seemed finally able to make their reorganizations stick. Many reworked their touring calendars and abandoned their big top in favor of performing in civic centers. John Ringling North sold his circus in 1968, and the new management made some revolutionary changes: they added a second touring unit and listed their circus on the stock market. While Ringling was doubling its operations, other consolidated groups were riding the trend as well, many leasing some of the older, well-known names such as Cole Bros. and 
Table 1. Characteristics of the four pathologies.

\begin{tabular}{lll}
\hline \hline Pathology & Characterized by & Description \\
\hline Poverty Trap & $\begin{array}{l}\text { Low Potential } \\
\text { Low Connectedness } \\
\text { Low Resilience }\end{array}$ & $\begin{array}{l}\text { Systems in a poverty trap have no capital, or potential to work with, nor is } \\
\text { there any level of solidarity or cooperation to bring the potential together. } \\
\text { Therefore, there is no ability to emerge from reorganization. }\end{array}$ \\
Rigidity Trap & $\begin{array}{l}\text { High Potential } \\
\text { High Connectedness }\end{array}$ & $\begin{array}{l}\text { Misappropriation, i.e., waste of resources, dogmatism, and orthodoxy make } \\
\text { these systems rigid, unable to change or innovate, and therefore vulnerable to } \\
\text { change/surprise. }\end{array}$ \\
Ligh Resilience & $\begin{array}{l}\text { Low Potential } \\
\text { High Connectedness }\end{array}$ & $\begin{array}{l}\text { Lock-in traps are often situations in which high levels of connectedness } \\
\text { between actors and high levels of institutional resilience maintain otherwise } \\
\text { maladaptive behaviors. Change is not possible because of the lack of potential }\end{array}$ \\
High Resilience & $\begin{array}{l}\text { High Potential } \\
\text { Low Connectivity }\end{array}$ & $\begin{array}{l}\text { These systems have the potential to be many things, but lack of connectivity } \\
\text { and resilience will prevent any particular combination from asserting itself, } \\
\text { especially when faced with even the most minor of perturbations. }\end{array}$
\end{tabular}

Sells Bros (Fox and Parkinson 1969, Oxley 2005, personal communication). It appeared as though the circus was finally emerging from the chaos.

However the 1970s and 1980s were a time of significant social change in America, and the reorganizations were not enough to make the old circus relevant to the new audiences. Circuses had always been the ultimate purveyor of spectacle, e. g., freak shows, exotic animals, and seemingly impossible human stunts. But changing attitudes toward human and animal rights forced them to discontinue the freak shows and most animal performances. The loss of these central components of circus subsistence was just too great a blow to the still unstable industry. A few small regional circuses hung on, like the Big Apple Circus of New York, but overall the industry was closing up shop (Grossman 1986).

\section{Not the only act in town}

Transportation and information technology was making the world smaller, and the spectacles that circuses sold became less and less spectacular. By the close of the twentieth century, television, the internet and the motion picture industry had completely overtaken the circus as a purveyor of the fantastic; television shows connected people at their homes to places all around the world, and special effects gave actors the ability to fly and perform superhuman feats. The American circus simply could not compete, and it began to fall into irrelevance. Only small fragments of the circus remained, found in state fair midways, street performances and second-rate amusement parks.

However, a new kind of circus was emerging in Europe and Canada, one that used no animals, no rings, and no big top. Instead, performers were uniting beneath the banner of performance art called "cirque nouveau." These troupes combined their traditional circus arts with an orchestral soundtrack, elaborate costumes and lighting, and a theme or storyline. Montreal's Cirque du Soleil is the best known, but other groups include San Francisco's New Pickle Circus and Australia's Circus Oz. Each of these found its own way to resurrect "circus" by reemphasizing its humanistic and artistic nature (Sparks 2002, Matthaeus 2003:48, Circus Center 2005, Circus Oz 2006). It was soon clear that the new formulas were a success; by 1984 Cirque $d u$ Soleil even began performing under a blue and yellow striped big top, as if exclaiming the circus's triumphant return (Cirque du Soleil 2005, Vigil 2005). 
Fig. 3. The chaos trap and the adaptive cycle, characterized by high potential, low resilience and low connectivity. Usually entered during reorganization; the system has potential to be many things, but lack of connectivity and resilience prevents assertion.

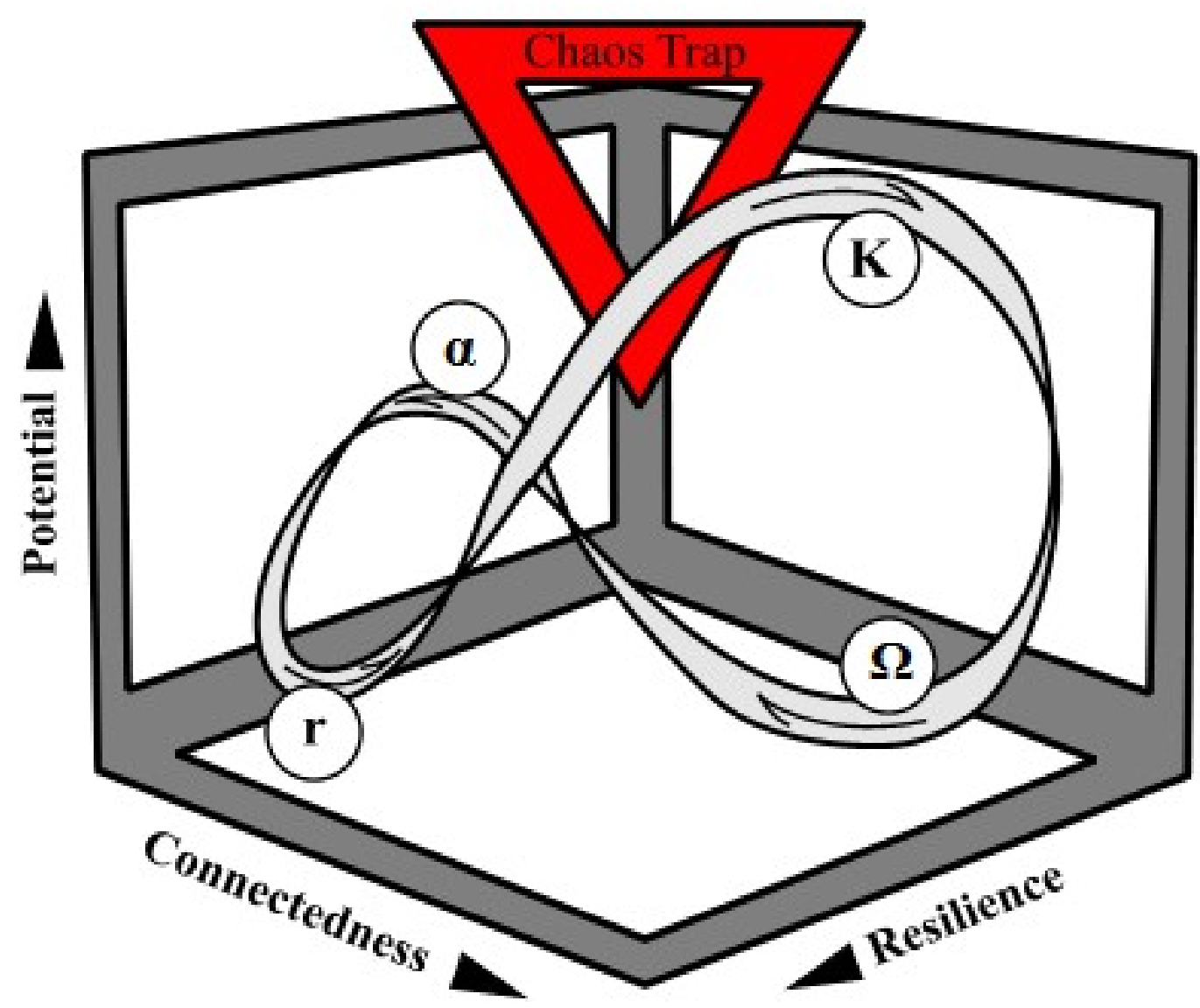

Twenty years later, "cirque" is a worldwide phenomenon. Cirque du Soleil now has a dozen touring shows and a permanent operation in Las Vegas. The New Pickle circus has become the performance arm of San Francisco's successful Circus Center School for Performing Arts (Circus Center 2005). Even traditional companies like The Big Apple Circus, Shrine Circus, and Ringling Bros. show the influence of this new movement, each testing their audiences with new combinations of old and new circus. By focusing on artistic composition, circuses have reinvested in the relationship with their audience by treating them not just as bystanders, but also as art lovers. Familiar circus legacies have also resurfaced; the Flying Wallendas and even clown king Bellow Nock, whose family has been practicing the art since the 1700s, are closely involved with Cirque du Soleil (Metz 2005). Still, the majority of new performers are not from traditional circus families (Vigil 2005); should this new cycle of circus prove resilient enough to keep the circus from chaos, perhaps these new performers' children will themselves be the start of new circus legacies that carry the industry through the 21 st century. 


\section{CONCLUDING REMARKS}

The circus is an example of long-term social sustainability that stands out, I think, as particularly insightful because it has persisted for so long, has such a well-documented history, and is a commonly known and admired institution that people of otherwise diverse backgrounds can relate to and discuss. In many respects circuses functioned like tribes, and their histories are rich in examples of social resilience: for example how performing families contributed redundancy, solidarity and functional diversity to their circuses; how local knowledge allowed circuses to adapt to the nuances of local economies; how institutions such as the Zoological Institute and the Flatfoot Party provided layers of social capital capable of absorbing the downscale economic impacts of the Great Panic; and most notably how circuses, by incorporating change and innovation as tradition, were neither too rigid nor too locked-in to current regimes to respond effectively to change and uncertainty.

On a few rare occasions, however, the circus industry did seem like it was on its way out for good, most notably the recent period that I have characterized here as chaos. Following the metaphor of the adaptive cycle, the "chaos trap" is a previously unidentified period of Socio-ecological system vulnerability, following the release phase, where especially low levels of resilience can cause a system to repeatedly fail to reorganize. Normally, reorganizing systems are highly resilient; in chaos, mechanisms of resilience have been rendered impotent; and thus, any emerging partnerships or configurations are vulnerable to the smallest of stresses. This was the case for the circus; there was no shortage of talent, but struck by a long succession of economic stresses and marginalized by changing consumer sensibilities, new performance innovations were repeatedly undermined by the lack of a devoted audience and respected name to rely on. "Cirque nouveau" ultimately proved the key to emerging from this chaos: a common vision that generated new resilience and connectedness within the industry by uniting performers and improving troupe credibility through a reinvestment in the circus-audience relationship.

The livelihood and indeed the very identity of a performer and their circus community has proven fixed in this reciprocal relationship with the audience, i.e., the source of their subsistence, if you will, much in the same way that the identity of a
Native Alaskan and their tribal community remains rooted in Alaska's land and animals despite a comparable contemporary history of both internally and externally driven change (Gerlach et al. in press). Though countless particulars have changed for both systems over the years, "cirque" remains "circus" with, or without elephants just as Athabascan hunters are no more or less Athabascan should they travel by dog team or snow machine. If a sustainable social-ecological system is indeed one that both changes and persists, the test of that persistence, therefore, is not simply whether a predefined set of structures remain, but whether or not stakeholders continue to recognize, respect, and feel a belonging to the system after change has happened. This lesson seems especially relevant to situations of ecosystem and resource comanagement, in which all the right pieces appear to be in place for effective collaboration toward sustainability and change, but no headway is made in achieving stakeholder consensus or followthrough, characterized perhaps by a number of false starts or stakeholder conflict. Overcoming such chaos requires a vision that does not shy from innovation but also does not abandon or ignore what came before. To understand this is to understand the local context within which we work, the way that tradition can shape change rather than stand in its way, and is requisite to developing healthier and more sustainable communities and ecosystems.

Responses to this article can be read online at:

http://www.ecologyandsociety.org/vol12/iss1/art9/responses/

\section{Acknowledgments:}

First and foremost I must extend my gratitude to the contributions made to this paper by the anonymous reviewer, without which I fear my message would have been lost. Much thanks also goes to Craig Gerlach, Terry Chapin, and Gary Kofinas for their respective guidance and support. Thanks to Lance Gunderson for your thoughts and for facilitating the review process. It was a delight to meet Phil Oxley, who in a past life spent a season with the Sells Brother's Circus. And finally, thanks to Esther Sampol, Alys a Klistoff and Martin Robards for their reviews and encouragement. This research effort was supported by a fellowship from the USDA's Sustainable Agriculture Research and Education program, Western Region (WSARE) and the 
University of Alaska Fairbanks' Resilience and Adaptation Program (RAP).

\section{LITERATURE CITED}

Allison, H. E., and R. J. Hobbs. 2004. Resilience, adaptive capacity, and the "lock-in trap" of the western Australian agricultural region. Ecology and Society 9(1):3-27. [online] URL: http://www.ecolo gyandsociety.org/vol9/iss1/art3/.

Bergengren, R. 1909. Taking the circus seriously. In M. S. Fenner and W. Fenner, editors. The circus: lure and legend. Prentice-Hall, Englewood Cliffs, New Jersey, USA.

Circus Center. 2002. About us. [online] URL: http ://www.circuscenter.org/about/about oview.html.

Circus Oz. 2006. About Circus Oz. [online] URL: http://www.circusoz.com/ViewPage.action? siteNodeId=103\&languageId=1\&contentId=-1.

Cirque du Soleil. 2005. History. [online] URL: htt p://www.cirquedusoleil.com/CirqueDuSoleil/en/company/ behind/history.htm.

Clement, H. 1974. The circus, bigger and better than ever? A. S. Barnes. Cranbury, New Jersey, USA.

Cumming, J. S., and J. Collier. 2005. Change and identity in complex systems. Ecology and Society 10(1) [online] URL: http://www.ecologyandsociety. org/vol10/iss 1/art29/

Fellows, D., and A. A. Freeman. 1936. This way to the big show: the life and times of Dexter Fellows. Halcyon House, New York, New York, USA.

Fenner, M. S., and W. Fenner, editors. 1970. The circus: lure and legend. Prentice-Hall, Englewood Cliffs, New Jersey, USA.

Fox, C. P., and T. Parkinson. 1969. The circus in America. Country Beautiful, Waukesha, Wisconsin, USA.

Gerlach S. C., A. M. Turner, L. Henry, P. Loring, and C. Fleener. In Press. Regional foods, food systems, security and risk in rural Alaska. In L. K.
Duffy, editor. Circumpolar environmental science: current issues in resources, health and policy. University of Alaska Press, Fairbanks, Alaska, USA.

Grossman, R. 1986. The smallest show on earth. Chicago Tribune, 7/10/1986:1.

Holling, C. S., and G. K. Meffe. 1996. Command and control and the pathology of natural resource management. Conservation Biology 10(2):328-337.

Holling, C. S., and L. H. Gunderson. 2002. Panarchy: resilience and adaptive cycles. Pages 25-65 in L. H. Gunderson and C. S. Holling, editors. Panarchy: understanding transformations in human and natural systems. Island Press, Washington, D. C., USA.

Holling, C. S., L. H. Gunderson, and G. D. Peterson. 2002. Panarchy: sustainability and panarchies. Pages 63-102 in L. H. Gunderson and C. S. Holling, editors. Panarchy: understanding transformations in human and natural systems. Island Press, Washington, D.C., USA.

Matthaeus, P. 2003. They say they want a revolution: what marketers need to know as consumers take control. iUniverse.com, Lincoln, Nebraska, USA.

Metz, N. 2005. High wire act. Chicago Tribune 9/9/2005:1.

Parkinson, W. A. 1999. The social organization of early copper age tribes on the Great Hungarian Plain. 64th Annual Meeting of The Society for American Archaeology 1:1-10.

Powledge, F. 1976. Born on the circus. Harcourt Brace Jovanovich, New York, New York, USA.

Quinn, D. 1999. Beyond civilization: humanity's next great adventure. Harmony Books, New York, New York, USA.

Sparks, A. 2002. Circus. In A. Hughes and K. Reader, editors. Encyclopedia of contemporary French culture. Routledge, London, UK.

Trosper R. L. 2003. Resilience in pre-contact Pacific Northwest social ecological systems. Conservation Ecology 7(3):1-12. 
Vigil, D. 2005. Clowning around is serious business. San Francisco Chronicle 8/31/2005:1.

Wilmeth, D. B. 1982. Variety entertainment and outdoor amusements: a reference guide. Greenwood Press, Westport, Connecticut, USA.

Zuckoff, M. 1992. Under the little top. Boston Globe 7/5/1992:10. 